\title{
Left Ventricular Adaptations in Herding Dogs
}

\author{
Raimy Costa Martins, João Paulo da Exaltação Pascon, Karen Guzmán Béltran \& Maria Ligia de Arruda Mistieri
}

\begin{abstract}
Background: Athlete's heart syndrome comprises a set of functional and anatomic cardiac changes secondary to intense and prolonged physical exercise in humans and animals. The heart adapts to the type of activity performed, and Doppler echocardiography is the best tool for identifying these changes. Speckle tracking echocardiography (STE) has provided new data on cardiovascular adaptations secondary to physical exercise in humans, information that conventional echocardiography cannot provide. Although physical activity and work in dogs are well documented, there are few studies on cardiovascular adaptations secondary to exercise in dogs, and no studies to date evaluated these adaptations using STE.

Materials, Methods \& Results: A total of $31 \mathrm{dogs}$ of the Border Collie and Ovelheiro Gaúcho Brasileiro breeds were divided into two groups: a herding group $(\mathrm{HG}, \mathrm{n}=15)$, which performed herding activity five to six times a week for at least 4 months, and a sedentary group ( $\mathrm{SG}, \mathrm{n}=16$ ), with no history of physical activity in the past twelve months. All dogs were previously subjected to electrocardiography and blood pressure measurement. After that, the animals underwent echocardiographic examination at rest at a single time point. The data were analyzed by two-way multivariate analysis of variance (ANOVA) at a level of significance of 5\% $(P<0.05)$ and a trend at $90 \%(P<0.1)$. The dogs of the HG had higher values for left-ventricular end-systolic diameter (LVESD) and systolic volume (SV), and lower values for leftventricular myocardial performance index (Tei index) and systolic septal movement. STE results indicated that the HG presented lower values for strain and strain rate in some myocardial segments in the radial, circumferential, longitudinal, and transverse directions.

Discussion: The increase in LVESD is justified by the increase in preload (volume) required to meet the increased oxygen demand, whereas SV is directly related to the Frank-Starling mechanism. The lower Tei index in the HG indicates better systolic-diastolic performance, explained by a shorter isovolumetric relaxation time and isovolumetric contraction time and by an increase in left ventricular (LV) ejection time. Similar results were not observed in LV systolic wall motion. Therefore, we believe that the most likely explanation is a higher systolic efficiency, associated with lower energy demand at rest. According to STE criteria, the lower strain and strain rate in the HG in some myocardial segments in all directions suggest less need for myocardial deformation and lower deformation velocity in order to maintain systolic function. In conclusion, conventional echocardiography and STE were complementary and fundamental to understand cardiovascular adaptations in herding dogs.
\end{abstract}

Keywords: echocardiography, canine, physical activity. 


\section{INTRODUCTION}

The term "athlete's heart" is often used to define major cardiac adaptations to physical exercise $[19,36]$, including the increase in internal diameter, wall thickness, and mass of the left ventricle (LV) $[31,36]$. However, different types, intensities, durations, and frequencies of physical activity result in distinct cardiac adaptations [19,29].

In this context, Doppler echocardiography stands out as a useful tool to evaluate these cardiac adaptations in animals [1,27,40,49] and humans [4]. Recent techniques of tissue velocity imaging (TVI) and speckle tracking echocardiography (STE) have brought new knowledge about myocardial deformation [12], contributing significantly to sports medicine $[17,30]$.

STE allows determining the strain (ST) and strain rate (STR) of LV myocardial deformation in orthogonal planes in the radial, longitudinal, and circumferential directions, and in tangential planes, caused by the sliding of muscle layers from the endocardium to the epicardium [18]. Although these variables have been validated in dogs $[9,11,50]$ and have been used to evaluate heart diseases $[15,38,43]$, the behavior of these variables relative to adaptations promoted by physical activities like snow sled pulling [40] agility competitions [34], running competitions [27] and herding $[2,5,22,41,51]$ remains unknown.

Therefore, aiming to better understand the herding activity in dogs and its hemodynamic consequences, the objective of this study was to present the behavior of morphological and functional echocardiographic variables, as well as variables related to the systolic function of the LV, both conventional and current (TVI and STE), compared to sedentary dogs.

\section{MATERIALS AND METHODS}

\section{Animal selection}

The present study was approved by the Animal Research Ethics Committee of the Federal University of Pampa under Protocol No. 038/2015. Thirty-five dogs of the Border Collie and Ovelheiro Gaúcho Brasileiro breeds were previously evaluated by electrocardiography, Doppler echocardiography, peripheral blood pressure measurement, and clinical assessment to ensure that only healthy animals were included in the study. Two dogs with canine visceral leishmaniasis, one with myxomatous mitral valve disease and another with a high level of stress during echocardiographic evaluation, were excluded from the study, totaling 31 dogs, and these animals were subdivided into a sedentary group (SG) and a herding group (HG) according to the level of physical activity.

The SG consisted of 16 dogs with no history of physical activity or work for at least 12 months, whereas the HG included 15 dogs that performed physical activity 5 to 6 times a week for at least 4 months (29.46 \pm 25.44 months). The HG performed its daily activities in a morning shift $(3.44 \pm 0.88 \mathrm{~h})$ and an evening shift (3.88 $\pm 0.92 \mathrm{~h})$, totaling an average of $5.2 \pm 2.33 \mathrm{~h}$ of daily activity. Further information on the breed, gender, weight, and age of the study groups is shown in Table 1.

\section{Echocardiographic examinations}

Two-dimensional (2D), one-dimensional (M-mode), and Doppler (spectral and color) echocardiography, TVI, and STE scans were acquired using an MyLab Twice Vet ultrasonographic ${ }^{1}$ device with multi-frequency transducers (3-5 MHz and 4-11 $\mathrm{MHz}$ ). Index electrocardiograms were also obtained, without sedation or anesthesia, according to the recommendations of authors $(6,13)$. The morphological and systolic function variables were analyzed offline using a MyLabDesk platform ${ }^{1}$ and were measured three times by a single evaluator blind to group allocation.

For morphological analysis, the LV internal diameter (LVID) thickness, LV free wall (LVFW) thickness, and interventricular septum (IVS) thickness at end-systole and end-diastole were obtained in the right parasternal view in the chordal plane in M-mode. In the same image, the ejection fraction (EF) [26], shortening fraction (SF) [45], stroke volume (SV), LV mass, and LV mass index were calculated [46]. The diameter of the left atrium, aorta, and the left atrium to aortic diameter ratio were measured in the right parasternal view in the two-dimensional mode [21].

The isovolumetric relaxation time, isovolumetric contraction time, and aortic flow ejection time were obtained in the apical five-chamber view, allowing the later calculation of the LV's global myocardial performance index (Tei index) [44]. Similarly, the LV septal and parietal TVI were obtained in the apical four-chamber view [14].

STE was used to determine LV systolic myocardial deformation (ST and STR) in the radial, circumferential, longitudinal, and transversal direc- 
tions, according to literature recommendations [9]. The myocardial musculature was tracked by automatically demarcating the endocardial and epicardial borders at end-systole using the Aided Heart Segmentation system, and was later adjusted by the evaluator to optimize speckle tracking in the images.

ST and STR values were obtained for the anterior-septal, anterior, lateral, posterior, inferior, and septal segments in the circumferential and radial directions, and for the basal-septal, basal-lateral, medialseptal, medial-lateral, apical-septal, and apical-lateral segments in the longitudinal and transversal directions. The ST and STR values of the epicardial and endocardial borders were also separately evaluated in the longitudinal and circumferential directions.

\section{Statistical analysis}

All statistical analyses were performed by pairwise analysis of variance (ANOVA) using SPSS software version 20.0 (IBM SPSS Statistics) at a 5\% level of significance $(P<0.05)$ and a trend of $10 \%(P<0.1)$.

\section{RESULTS}

The ANOVA results indicated the absence of significant differences in body weight, age, and breeds between the SG and HG $(P>0.05)$ [Table 1]. Similarly, gender did not significantly affect the echocardiographic parameters in the two groups $(P>0.05)$. With respect to heart morphology-related variables (Table 2), LVID was significantly larger in the HG than in the SG $(P<0.05)$, but there were no significant intergroup differences in LVFW and IVS thickness.

The systolic function indicator variables (SV and Tei index) were significantly different between the groups $(P<0.05)$ [Table 3$]$. The $\mathrm{SV}$ was significantly larger in the HG than in the SG, whereas the Tei index was significantly lower in the HG than in the SG $(P$ $<0.05$ ) [Table 3].

EF and SF were not significantly different between the groups (Table 3). In turn, the septal peak systolic velocity $(\mathrm{Sm})$ was significantly lower $(P<$ 0.05) in the HG than in the SG (Table 3).

Segmental and total ST and STR were significantly different between the groups in the four directions using the STE technique. In the radial direction, the STRs of the septal and anterior-septal segments were significantly higher in the SG than in the HG $(P<0.05)$ [Table 4]. Similarly, in the circumferential direction, the STR of the lateral, inferior, posterior, septal, and total (average of all segments) segments was significantly higher in the SG than in the HG $(P<0.05)$ [Table 5]. However, in the epicardial and endocardial borders, the systolic STR of the anteriorseptal, anterior, and total segments, the systolic STR of the anterior segment, the global ST, and the ST of the inferior segment showed a trend to higher values in the SG relative to the $\mathrm{HG}(P<0.1)$.

In the longitudinal direction of myocardial deformation, the ST values of the basal-septal and medial-septal segments of the epicardium were higher in the SG than in the HG $(P<0.05)$, and there was a trend to a higher global mean in the SG compared with the HG $(P<0.1)$ [Table 6]. Similarly, in the transversal direction, the ST values of the basal-septal and medialseptal segments were higher in the SG than in the HG $(P<0.05)$ [Table 7].

\section{DISCUSSION}

The results on the structural parameters of the heart (LVID, IVS, and LVFW) indicated that the herding activity performed by dogs resulted in a predominantly isotonic adaptation [40], similar to what was observed in rats subjected to swimming programs [20] and in human marathonists [32]. The isotonic activities promote an increase in venous return (preload) to meet the greater oxygen demand in the muscles. In the long term, this volumetric overload induces eccentric hypertrophy of the LV to maintain a constant parietal stress and adequate SV [30,48].

The highest SV found in the HG was similar to that found in human athletes practicing isotonic activities, such as swimming, running, soccer, and basketball for 15 to 20 hours a week for longer than four years compared with an SG [7]. The SV is intrinsically correlated with preload, and thus the volumetric overload imposed by the herding activity induced an increase in SV, according to the Frank-Starling mechanism [7,39].

In a study involving human sprinters and marathoners, the lower Tei index in athletes was due to a reduction in isovolumetric relaxation and contraction times, and to an increase in the LV ejection time [48], indicating better myocardial function [23]. Therefore, it was hypothesized that the variables that compose this index were affected by physical conditioning resulting from herding practices, leading to improved overall cardiovascular (systolic and diastolic) efficiency. 
Table 1. Characterization of the study groups regarding the animal breed, gender, weight, and age.

\begin{tabular}{cccc}
\hline & Characteristics & Sedentary dogs & Herding dogs \\
\hline \multirow{2}{*}{ Breed } & Ovelheiro Gaúcho - n (\%) & $7(58.33)$ & $5(41.66)$ \\
& Border Collie - n (\%) & $9(47.36)$ & $10(52.63)$ \\
Gender & Male - n (\%) & $5(33.33)$ & $10(67.67)$ \\
\multirow{2}{*}{ Weight } & Female (\%) & $11(66.67)$ & $5(33.33)$ \\
Age & Mean (kg) \pm standard deviation & $18.9 \pm 0.86$ & $20.22 \pm 1.06$ \\
Total & Mean (years) \pm standard deviation & $3.94 \pm 0.60$ & $4.38 \pm 0.57$ \\
\hline
\end{tabular}

Table 2. Structural echocardiographic variables in herding and sedentary dogs.

\begin{tabular}{cccc}
\hline Variable & Herding dogs & Sedentary dogs & $P$-value \\
\hline LVDd $(\mathrm{cm})$ & $3.98 \pm 0.12$ & $3.73 \pm 0.12$ & 0.147 \\
LVDs $(\mathrm{cm})$ & $2.72 \pm 0.09$ & $2.43 \pm 0.06$ & $0.031^{*}$ \\
IVSd $(\mathrm{cm})$ & $0.87 \pm 0.04$ & $0.85 \pm 0.04$ & 0.762 \\
IVSs $(\mathrm{cm})$ & $1.17 \pm 0.05$ & $1.09 \pm 0.05$ & 0.325 \\
LVFWd $(\mathrm{cm})$ & $0.77 \pm 0.04$ & $0.85 \pm 0.04$ & 0.168 \\
LVFWs $(\mathrm{cm})$ & $0.99 \pm 0.06$ & $1.04 \pm 0.06$ & 0.532 \\
LA/AO ratio & $1.41 \pm 0.05$ & $1.42 \pm 0.05$ & 0.862 \\
LVM $(\mathrm{g})$ & $114.65 \pm 10.65$ & $100.94 \pm 10.48$ & 0.672 \\
LVMI $\left(\mathrm{g} \mathrm{m}^{2}\right)$ & $158.65 \pm 12.08$ & $131.56 \pm 11.90$ & 0.122 \\
\hline
\end{tabular}

LVDd= end-diastolic left ventricular diameter; LVDs= end-systolic left ventricular diameter; IVSd= end-diastolic interventricular septum thickness; IVSs= end-systolic interventricular septum thickness; LVFWd= end-diastolic left ventricular free wall thickness; LVFWs= end-systolic left ventricular wall thickness; $\mathrm{LA} / \mathrm{AO}=$ ratio between the left atrial diameter and the aortic diameter; $\mathrm{LVM}=$ left ventricular mass; $\mathrm{LVMI}=$ left ventricular mass index; * = significantly different at $P<0.05$.

Table 3. Echocardiographic variables related to systolic function in herding and sedentary dogs.

\begin{tabular}{cccc}
\hline Variable & Herding dogs & Sedentary dogs & $P$-value \\
\hline EF $(\%)$ & $60.60 \pm 1.397$ & $62.69 \pm 2.037$ & 0.161 \\
SF $(\%)$ & $31.70 \pm 1.42$ & $34.45 \pm 1.40$ & 0.179 \\
CO (L/min) & $3.81 \pm 0.395$ & $3.76 \pm 0.456$ & 0.626 \\
PFV $(\mathrm{m} / \mathrm{s})$ & $0.95 \pm 0.046$ & $0.90 \pm 0.395$ & 0.574 \\
AFV (m/s) & $1.24 \pm 0.059$ & $1.28 \pm 0.048$ & 0.630 \\
Sm par $(\mathrm{m} / \mathrm{s})$ & $0.17 \pm 0.01$ & $0.18 \pm 0.01$ & 0.479 \\
Sm sep $(\mathrm{m} / \mathrm{s})$ & $0.13 \pm 0.01$ & $0.15 \pm 0.01$ & $0.044^{*}$ \\
LV Tei index & $0.37 \pm 0.03$ & $0.46 \pm 0.03$ & $0.030^{*}$ \\
CI $\left(\mathrm{L} / \mathrm{min} / \mathrm{m}^{2}\right)$ & $5.42 \pm 0.557$ & $5.1 \pm 0.537$ & 0.949 \\
SV $(\mathrm{mL})$ & $28.89 \pm 2.394$ & $22.11 \pm 1.528$ & $0.049 *$ \\
\hline
\end{tabular}

$\mathrm{EF}=$ ejection fraction; $\mathrm{SF}=$ shortening fraction; $\mathrm{CO}=$ cardiac output; $\mathrm{PFV}=$ pulmonary flow velocity; $\mathrm{AFV}=$ aortic flow velocity; $\mathrm{Sm}$ par= parietal peak systolic velocity; $\mathrm{Sm}$ sep= septal peak systolic velocity; LV Tei index= left ventricular global myocardial performance (Tei) index; CI= cardiac index; $\mathrm{SV}=$ stroke volume; ${ }^{*}=$ significantly different at $P<0.05$. 
Table 4. Strain (ST) and strain rate (STR) in the radial direction obtained by speckle tracking echocardiography in herding and sedentary dogs.

\begin{tabular}{ccccc}
\hline Segment & Variable & Herding dogs & Sedentary dogs & $P$-value \\
\hline \multirow{2}{*}{ Anterior-septal } & ST $(\%)$ & $23.294 \pm 3.832$ & $34.24 \pm 3.774$ & 0.750 \\
& STR $\left(\mathrm{s}^{-1}\right)$ & $2.202 \pm 0.250$ & $2.958 \pm 0.246$ & $0.041^{*}$ \\
Anterior & ST $(\%)$ & $29.722 \pm 3.900$ & $32.887 \pm 3.840$ & 0.568 \\
& STR $\left(\mathrm{s}^{-1}\right)$ & $2.531 \pm 0.256$ & $2.718 \pm 0.252$ & 0.607 \\
Lateral & ST $(\%)$ & $30.439 \pm 3.812$ & $31.319 \pm 3.754$ & 0.871 \\
& STR $\left(\mathrm{s}^{-1}\right)$ & $2.535 \pm 0.229$ & $2.381 \pm 0.226$ & 0.637 \\
Posterior & ST $(\%)$ & $26.610 \pm 3.633$ & $30.539 \pm 3.578$ & 0.448 \\
& STR $\left(\mathrm{s}^{-1}\right)$ & $2.231 \pm 0.194$ & $2.178 \pm 0.191$ & 0.848 \\
Inferior & ST $(\%)$ & $21.157 \pm 3.748$ & $29.771 \pm 3.691$ & 0.113 \\
& STR $\left(\mathrm{s}^{-1}\right)$ & $2.056 \pm 0.162$ & $2.382 \pm 0.160$ & 0.163 \\
Septal & ST $(\%)$ & $20.416 \pm 3.905$ & $31.574 \pm 3.846$ & 0.720 \\
& STR $\left(\mathrm{s}^{-1}\right)$ & $2.111 \pm 0.169$ & $2.670 \pm 0.184$ & $0.043 *$ \\
Global average & ST $(\%)$ & $25.439 \pm 3.458$ & $31.574 \pm 3.406$ & 0.217 \\
& STR $\left(\mathrm{s}^{-1}\right)$ & $2.277 \pm 0.179$ & $2.548 \pm 0.176$ & 0.293 \\
\hline
\end{tabular}

* $=$ significantly different at $P<0.05$.

The EF and SF values found in this study were similar to those found in sled dogs trained for five months [40]. However, higher SF values were found in race greyhounds trained for three months compared with sedentary animals [27]. The absence of significant differences between the two groups may be because the contractility indexes are directly affected by the preload, afterload, and/or heart rate [13].

A previous study reported that Sm values were higher in human athletes practicing marathon and canoeing than in sedentary individuals [47]. However, there was no significant difference between athletes practicing marathon, weightlifting, swimming, soccer, basketball, martial art, windsurfing, and a control group [16]. It was hypothesized that a higher systolic efficiency associated to a lower energy demand at rest were the main contributing factors for this difference. Therefore, the decrease in this variable in the HG indicates lower cardiovascular energy consumption and better performance when associated with a better systolic function, demonstrated by the SV and Tei index. However, although there were no difficulties in angulation, such errors should be considered as a source of variation [10].

With regard to the STE technique, despite the higher values obtained in the radial and circumferential directions, these values do not reflect higher pumping efficiency, considering that SV values were higher in the HG, indicating the higher systolic efficiency of the dogs from this group. To the best of our knowledge, no studies to date used this echocardiographic modality to evaluate athletic cardiac performance in dogs. However, the ST values in the anterior-septal and septal segments in the circumferential direction were decreased in humans undergoing isotonic and isometric training [3]. It is plausible to consider that the circumferential myocytes of the right ventricle also encompass the IVS region. Therefore, it is also plausible to consider this factor as an influence toward lower ST values in the segments surrounding the IVS region (anterior-septal, septal, and inferior) in the HG.

Another relevant factor is that the right parasternal view in the transversal axis and in the papillary plane, used to acquire the LV transversal image and calculate the ST and STR of the segments, may have limited the tracking of speckles on the epicardial border of the anterior-septal, septal, and anterior segments, because of the proximity of these segments to the echocardiographic probe. This technical limitation may have affected the results of epicardial parameters evaluated in the circumferential direction.

Similar to the radial and circumferential direction, the higher deformation measurements in the longitudinal direction in the SG could not compensate for the larger LV diameter in the $\mathrm{HG}$, resulting in a lower SV in the SG. A controversial result was found 
Table 5. Strain (ST) and strain rate (STR) of the endocardium (End) and epicardium (Epi) in the circumferential direction obtained by speckle tracking echocardiography in herding and sedentary dogs.

\begin{tabular}{|c|c|c|c|c|c|}
\hline Segment & Border & Variable & Herding dogs & Sedentary dogs & $P$-value \\
\hline \multirow{4}{*}{ Anterior-septal } & \multirow{2}{*}{ Epi } & $\mathrm{ST}(\%)$ & $5.380 \pm 0.823$ & $5.831 \pm 0.810$ & 0.698 \\
\hline & & $\operatorname{STR}\left(\mathrm{s}^{-1}\right)$ & $0.560 \pm 0.072$ & $0.753 \pm 0.071$ & $0.065^{¥}$ \\
\hline & \multirow{2}{*}{ End } & $\mathrm{ST}(\%)$ & $18.65 \pm 2.154$ & $23.70 \pm 2.121$ & 0.106 \\
\hline & & $\operatorname{STR}\left(\mathrm{s}^{-1}\right)$ & $1.954 \pm 0.231$ & $2.413 \pm 0.228$ & 0.168 \\
\hline \multirow{4}{*}{ Anterior } & \multirow{2}{*}{ Epi } & $\mathrm{ST}(\%)$ & $19.74 \pm 2.329$ & $24.51 \pm 2.294$ & 0.156 \\
\hline & & $\operatorname{STR}\left(\mathrm{s}^{-1}\right)$ & $0.546 \pm 0.084$ & $0.764 \pm 0.082$ & $0.073^{¥}$ \\
\hline & \multirow{2}{*}{ End } & $\mathrm{ST}(\%)$ & $19.74 \pm 2.329$ & $24.51 \pm 2.294$ & 0.155 \\
\hline & & $\operatorname{STR}\left(\mathrm{s}^{-1}\right)$ & $1.924 \pm 0.260$ & $2.649 \pm 0.256$ & $0.057^{¥}$ \\
\hline \multirow{4}{*}{ Lateral } & \multirow{2}{*}{ Epi } & $\mathrm{ST}(\%)$ & $6.259 \pm 1.114$ & $6.863 \pm 1.097$ & 0.702 \\
\hline & & $\operatorname{STR}\left(\mathrm{s}^{-1}\right)$ & $0.646 \pm 0.084$ & $0.840 \pm 0.083$ & 0.112 \\
\hline & \multirow{2}{*}{ End } & $\mathrm{ST}(\%)$ & $18.79 \pm 2.65$ & $23.78 \pm 2.613$ & 0.192 \\
\hline & & $\operatorname{STR}\left(\mathrm{s}^{-1}\right)$ & $1.904 \pm 0.277$ & $2.703 \pm 0.273$ & $0.049 *$ \\
\hline \multirow{4}{*}{ Posterior } & \multirow{2}{*}{ Epi } & $\mathrm{ST}(\%)$ & $7.164 \pm 1.082$ & $7.07 \pm 1.066$ & 0.951 \\
\hline & & $\operatorname{STR}\left(\mathrm{s}^{-1}\right)$ & $0.721 \pm 0.096$ & $0.844 \pm 0.095$ & 0.369 \\
\hline & \multirow{2}{*}{ End } & $\mathrm{ST}(\%)$ & $17.07 \pm 2.307$ & $22.48 \pm 2.27$ & 0.105 \\
\hline & & $\operatorname{STR}\left(\mathrm{s}^{-1}\right)$ & $1.847 \pm 0.235$ & $2.566 \pm 0.232$ & $0.038^{*}$ \\
\hline \multirow{4}{*}{ Inferior } & \multirow{2}{*}{ Epic } & $\mathrm{ST}(\%)$ & $6.297 \pm 1.035$ & $6.005 \pm 1.019$ & 0.842 \\
\hline & & $\operatorname{STR}\left(\mathrm{s}^{-1}\right)$ & $0.676 \pm 0.101$ & $0.816 \pm 0.100$ & 0.333 \\
\hline & \multirow{2}{*}{ End } & $\mathrm{ST}(\%)$ & $16.04 \pm 2.049$ & $21.16 \pm 2.018$ & $0.08^{¥}$ \\
\hline & & $\operatorname{STR}\left(\mathrm{s}^{-1}\right)$ & $1.688 \pm 0.206$ & $2.506 \pm 0.203$ & $0.008^{*}$ \\
\hline \multirow{4}{*}{ Septal } & \multirow{2}{*}{ Epi } & $\mathrm{ST}(\%)$ & $5.862 \pm 0.884$ & $6.006 \pm 0.870$ & 0.907 \\
\hline & & $\operatorname{STR}\left(\mathrm{s}^{-1}\right)$ & $0.681 \pm 0.090$ & $0.854 \pm 0.089$ & 0.182 \\
\hline & \multirow{2}{*}{ End } & $\mathrm{ST}(\%)$ & $17.53 \pm 2.06$ & $21.72 \pm 2.029$ & 0.158 \\
\hline & & $\operatorname{STR}\left(\mathrm{s}^{-1}\right)$ & $1.806 \pm 0.222$ & $2.527 \pm 0.219$ & $0.028^{*}$ \\
\hline \multirow{4}{*}{ Global average } & \multirow{2}{*}{ Epi } & ST $(\%)$ & $5.972 \pm 0.762$ & $6.343 \pm 0.750$ & 0.731 \\
\hline & & $\operatorname{STR}\left(\mathrm{s}^{-1}\right)$ & $0.638 \pm 0.065$ & $0.812 \pm 0.06$ & $0.065^{¥}$ \\
\hline & \multirow{2}{*}{ End } & $\mathrm{ST}(\%)$ & $17.97 \pm 2.011$ & $22.89 \pm 1.980$ & $0.092^{¥}$ \\
\hline & & $\operatorname{STR}\left(\mathrm{s}^{-1}\right)$ & $1.854 \pm 0.211$ & $2.561 \pm 0.208$ & $0.024 *$ \\
\hline
\end{tabular}

"= significantly different at $P<0.05 ; ¥=$ trend $(P<0.1)$.

in human athletes practicing wrestling (isometric) and marathon (isotonic) compared with an SG [37]. However, total ST values in the longitudinal direction were lower in human athletes practicing weightlifting, judo, and jujutsu (isometric) than in sedentary subjects [30]. The opposite was observed in rats subjected to $200 \mathrm{~min}$ of swimming five days a week for three months [24].

Baggish et al. [3] suggested that the involvement of septal regions of the epicardium in the $\mathrm{HG}$ may indicate a role of right ventricle adaptation in the longitudinal deformation of myocytes. The decrease in these values may be related to the lower sympathetic activity and higher parasympathetic activity due to physical training [35]. However, it is not possible to confirm these hypotheses considering only the present results, and further studies are necessary to address this question more conclusively.

No studies to date evaluated myocardial deformation in the transversal direction in dogs. However, ST values were lower in all transversal myocardial segments in handball practitioners undergoing isotonic and isometric training, compared with an SG [8]. In 
Table 6. Strain (ST) and strain rate (STR) of the epicardium (Epi) and endocardium (End) in the longitudinal direction obtained by speckle tracking echocardiography in herding and sedentary dogs.

\begin{tabular}{|c|c|c|c|c|c|}
\hline Segment & Border & Variable & Herding dogs & Sedentary dogs & $P$-value \\
\hline \multirow{4}{*}{ Septal-basal } & \multirow{2}{*}{ Epi } & $\mathrm{ST}(\%)$ & $15.033 \pm 2.010$ & $21.558 \pm 1.972$ & $0.031 *$ \\
\hline & & $\operatorname{STR}\left(\mathrm{s}^{-1}\right)$ & $1.670 \pm 0.307$ & $2.364 \pm 0.272$ & 0.107 \\
\hline & \multirow{2}{*}{ End } & $\mathrm{ST}(\%)$ & $14.483 \pm 2.415$ & $19.718 \pm 2.370$ & 0.137 \\
\hline & & $\operatorname{STR}\left(\mathrm{s}^{-1}\right)$ & $1.926 \pm 0.285$ & $2.314 \pm 0.253$ & 0.322 \\
\hline \multirow{4}{*}{ Medial-septal } & \multirow{2}{*}{ Epi } & $\mathrm{ST}(\%)$ & $11.227 \pm 1.527$ & $15.900 \pm 1.498$ & $0.040^{*}$ \\
\hline & & $\operatorname{STR}\left(\mathrm{s}^{-1}\right)$ & $1.185 \pm 0.187$ & $1.803 \pm 0.166$ & 0.230 \\
\hline & \multirow{2}{*}{ End } & $\mathrm{ST}(\%)$ & $15.411 \pm 2.293$ & $19.732 \pm 2.250$ & 0.193 \\
\hline & & $\operatorname{STR}\left(\mathrm{s}^{-1}\right)$ & $1.716 \pm 0.226$ & $2.153 \pm 0.200$ & 0.163 \\
\hline \multirow{4}{*}{ Apical-septal } & \multirow{2}{*}{ Epi } & $\mathrm{ST}(\%)$ & $5.849 \pm 0.802$ & $6.134 \pm 0.788$ & 0.802 \\
\hline & & $\operatorname{STR}\left(\mathrm{s}^{-1}\right)$ & $0.706 \pm 0.142$ & $0.873 \pm 0.126$ & 0.390 \\
\hline & \multirow{2}{*}{ End } & $\mathrm{ST}(\%)$ & $15.685 \pm 2.395$ & $15.383 \pm 2.350$ & 0.929 \\
\hline & & $\operatorname{STR}\left(\mathrm{s}^{-1}\right)$ & $1.596 \pm 0.275$ & $1.568 \pm 0.244$ & 0.940 \\
\hline \multirow{4}{*}{ Basal-lateral } & \multirow{2}{*}{ Epi } & $\mathrm{ST}(\%)$ & $16.669 \pm 1.987$ & $20.464 \pm 1.950$ & 0.187 \\
\hline & & $\operatorname{STR}\left(\mathrm{s}^{-1}\right)$ & $1.958 \pm 0.386$ & $2.273 \pm 0.342$ & 0.549 \\
\hline & \multirow{2}{*}{ End } & $\mathrm{ST}(\%)$ & $14.859 \pm 2.422$ & $16.453 \pm 2.377$ & 0.796 \\
\hline & & $\operatorname{STR}\left(\mathrm{s}^{-1}\right)$ & $2.648 \pm 0.320$ & $2.092 \pm 0.284$ & 0.210 \\
\hline \multirow{4}{*}{ Medial-lateral } & \multirow{2}{*}{ Epi } & $\mathrm{ST}(\%)$ & $11.764 \pm 1.687$ & $14.520 \pm 1.656$ & 0.257 \\
\hline & & $\operatorname{STR}\left(\mathrm{s}^{-1}\right)$ & $1.958 \pm 0.386$ & $2.273 \pm 0.342$ & 0.332 \\
\hline & \multirow{2}{*}{ End } & $\mathrm{ST}(\%)$ & $13.237 \pm 2.037$ & $14.020 \pm 1.999$ & 0.643 \\
\hline & & $\operatorname{STR}\left(\mathrm{s}^{-1}\right)$ & $1.800 \pm 0.220$ & $1.657 \pm 0.195$ & 0.631 \\
\hline \multirow{4}{*}{ Apical-lateral } & \multirow{2}{*}{ Epi } & $\mathrm{ST}(\%)$ & $6.374 \pm 1.019$ & $7.444 \pm 1.000$ & 0.462 \\
\hline & & $\operatorname{STR}\left(\mathrm{s}^{-1}\right)$ & $0.641 \pm 0.137$ & $0.877 \pm 0.121$ & 0.214 \\
\hline & \multirow{2}{*}{ End } & $\mathrm{ST}(\%)$ & $13.957 \pm 2.298$ & $13.113 \pm 2.255$ & 0.796 \\
\hline & & $\operatorname{STR}\left(\mathrm{s}^{-1}\right)$ & $1.590 \pm 0.254$ & $1.375 \pm 0.226$ & 0.534 \\
\hline \multirow{4}{*}{ Global average } & \multirow{2}{*}{ Epi } & $\mathrm{ST}(\%)$ & $11.153 \pm 1.186$ & $14.337 \pm 1.164$ & $0.069^{¥}$ \\
\hline & & $\operatorname{STR}\left(\mathrm{s}^{-1}\right)$ & $1.244 \pm 0.200$ & $1.645 \pm 0.186$ & 0.169 \\
\hline & \multirow{2}{*}{ End } & $\mathrm{ST}(\%)$ & $14.605 \pm 1.408$ & $16.403 \pm 1.452$ & 0.396 \\
\hline & & $\operatorname{STR}\left(\mathrm{s}^{-1}\right)$ & $1.879 \pm 0.166$ & $1.860 \pm 0.147$ & 0.931 \\
\hline
\end{tabular}

* = statistical significance $(P<0.05)$; $¥=$ trend $(P<0.1)$.

contrast, human soccer players presented higher global transversal ST values compared with a control group [33]. These authors hypothesized that this difference might be due to the increased volume and the increased number of myocardial cells. Although no histological analysis was conducted in our sample, there was no significant intergroup difference in IVS and LVFW thickness on echocardiography, which decreases the likelihood of involvement of this mechanism in the evaluated dogs.

It is of note that the left parasternal and apical four-chamber views used to acquire the longitudinal image of the LV presented technical limitations. The longitudinal movement of the myocardium resulted 
Table 7. Strain (ST) and strain strain (STR) in the transversal direction obtained by speckle tracking echocardiography in herding and sedentary dogs.

\begin{tabular}{ccccc}
\hline Segment & Variable & Herding dogs & Sedentary dogs & $P$-value \\
\hline \multirow{2}{*}{ Basal-septal } & ST $(\%)$ & $11.338 \pm 6.358$ & $34.101 \pm 6.239$ & $0.018^{*}$ \\
& STR $\left(\mathrm{s}^{-1}\right)$ & $2.764 \pm 0.570$ & $3.526 \pm 0.559$ & 0.351 \\
Medial-septal & ST $(\%)$ & $17.842 \pm 5.636$ & $36.621 \pm 5.531$ & $0.027^{*}$ \\
& STR $\left(\mathrm{s}^{-1}\right)$ & $2.213 \pm 0.403$ & $3.063 \pm 0.395$ & 0.147 \\
Apical-septal & ST $(\%)$ & $27.840 \pm 4.887$ & $30.325 \pm 4.796$ & 0.720 \\
& STR $\left(\mathrm{s}^{-1}\right)$ & $9.971 \pm 3.616$ & $2.297 \pm 3.549$ & 0.145 \\
Lateral-basal & ST $(\%)$ & $12.573 \pm 13.86$ & $36.833 \pm 13.599$ & 0.225 \\
& STR $\left(\mathrm{s}^{-1}\right)$ & $2.386 \pm 0.857$ & $4.301 \pm 0.841$ & 0.126 \\
Medial-lateral & ST $(\%)$ & $16.901 \pm 12.45$ & $34.098 \pm 12.220$ & 0.336 \\
& STR $\left(\mathrm{s}^{-1}\right)$ & $2.059 \pm 0.771$ & $3.505 \pm 0.757$ & 0.195 \\
Apical-lateral & $\mathrm{ST}(\%)$ & $24.691 \pm 7.764$ & $29.872 \pm 7.619$ & 0.639 \\
& $\mathrm{STR}\left(\mathrm{s}^{-1}\right)$ & $2.165 \pm 0.491$ & $2.658 \pm 0.482$ & 0.482 \\
Medial total & $\mathrm{ST}(\%)$ & $18.531 \pm 5.762$ & $33.64 \pm 5.654$ & $0.075^{*}$ \\
& $\mathrm{STR}\left(\mathrm{s}^{-1}\right)$ & $3.593 \pm 0.732$ & $3.225 \pm 0.718$ & 0.723 \\
\hline
\end{tabular}

$=$ statistical significance $(P<0.05) ; ¥=$ trend $(P<0.1)$.

in the displacement of points to positions out of the imaging plane, preventing the proper tracking of the myocardium and consequently reducing the reliability of the data for some segments. Similar results were found in humans [25] and other animals [28].

Cardiovascular adaptations in herding dogs usually agree with Morgaroth's theory [31, 35], in which isotonic or dynamic exercises tend to promote LV hypertrophy, characterized primarily by an increase in the LVID. The decrease in ST and STR values in the HG suggests improved conditioning of myocardial muscles, due to the reduced need to shorten myocardial fibers in order to maintain or improve systolic function parameters. Our STE results were similar to those found in human athletes practicing isotonic or isometric activities [30,33,42,48] considering segmental and global values of ST and STR. However, interspecies differences and the type of training performed should also be considered.

The limitations of this study include the difficulty in acquiring images of the epicardial border of some animals in the apical four-chamber view. This limitation decreased the reliability of the measurements and even prevented adequate speckle tracking of these segments, which culminated in the exclusion of some images from the analysis. This difficulty was also reported by Carnabuci [9] and Mantovani [28]. Another limitation was the difficulty in standardizing the herding activity in different farms, which limited the accurate quantification of the volume and intensity of the activities performed by each animal. Furthermore, the greater number of males in the $\mathrm{HG}$ reflects the reality of rural properties in the southern region of Brazil where the study was conducted. However, despite the differences in gender between the groups, the results of multivariate ANOVA indicated that gender did not significantly affect the studied variables.

\section{CONCLUSION}

The results suggest that the physical activity performed by herding dogs resulted in structural cardiovascular adaptations, reflected by a larger LVID and functional adaptations, namely a higher SV, lower Tei index, and lower Sm sep, characterizing a predominance of isotonic activity. STE results demonstrated that ST and STR values were lower in herding dogs in the radial, circumferential, longitudinal, and transversal directions in some myocardial segments, particularly in the IVS, suggesting a reduced need for myocardial deformation to maintain systolic function in herding dogs at rest, when compared with sedentary animals. Therefore, the conventional (structural and functional) and tissue echocardiographic findings obtained by tissue Doppler and speckle tracking were complementary and fundamental to understanding cardiovascular adaptations in herding dogs. 


\section{MANUFACTURER}

${ }^{1}$ Esaote Co. Milan, Italy

Ethical approval. All procedures, treatments and animal care were in compliance with the guidelines of the Italian minister of health for the care and use of animals (D.L.27/171992 325 n.116) and UE (Directive 86/609/CEE).

Acknowledgements. We are grateful to PPGCA (Graduate
Program in Animal Science) and CAPES (Coordination for the Improvement of Higher Level Personnel) for the opportunity, and Matheus Montano and Marília Valandro for the support and help. Special thanks to Mirela Noro, who helped to statistical analysis.

Declaration of interest. The authors report no conflicts of interest. The authors alone are responsible for the content and writing of paper.

\section{REFERENCES}

1 Amory H., Votion D.M., Fraipont A., Goachet A.G., Robert C., Farnir F. \& Van Erck E. 2010. Altered systolic left ventricular function in horses completing a long distance endurance race. Equine Veterinary Journal. 42(38): $216-219$.

2 Arnott E.R., Early J.B., Wade C.M. \& McGreevy P.D. 2014. Environmental factors associated with success rates of Australian stock herding dogs. PloS One. 9(8): 1-13.

3 Baggish A.L., Wang F., Weiner R.B., Elinoff J.M., Tournoux F., Boland A., Picard M.H., Huuter A.M. \& Wood M.J. 2008. Training-specific changes in cardiac structure and function: a prospective and longitudinal assessment of competitive athletes. Journal of Applied Physiology. 104(4): 1121-1128.

4 Barbier J., Ville N., Kervio G., Walther G. \& Carré F. 2006. Sports-specific features of athlete's heart and their relation to echocardiographic parameters. Herz Kardiovaskuläre Erkrankungen. 31(6): 531-543.

5 Barreto E.S.B. 2015. Por dez vacas com cria eu não troco meu cachorro': as relações entre humanos e cães nas atividades pastoris do pampa brasileiro. 131f. Pelotas, RS. Dissertação (Mestrado em Antropologia) - Programa de Pós-graduação em Antropologia, Universidade Federal de Pelotas.

6 Boon J.A. 2011. Evaluation of size, function, and hemodynamics. In: Veterinary Echocardiography. 2nd edn. Hoboken: Wiley-Blackwel, pp.151-260.

7 Boutcher S.H., McLaren, P.F., Cotton Y. \& Boutcher Y. 2003. Stroke volume response to incremental submaximal exercise in aerobically trained, active, and sedentary men. Canadian Journal of Applied Physiology. 28(1): 12-26.

8 Butz T., Van Buuren F., Mellwig K.P., Langer C., Plehn G., Meissner A. \& Faber L. 2011. Two-dimensional strain analysis of the global and regional myocardial function for the differentiation of pathologic and physiologic left ventricular hypertrophy: a study in athletes and in patients with hypertrophic cardiomyopathy. The International Journal of Cardiovascular Imaging. 27(1): 91-100.

9 Carnabuci C., Hanås S., Ljungvall I., Tidholm A., Bussadori C., Häggström J. \& Höglund K. 2013. Assessment of cardiac function using global and regional left ventricular endomyocardial and epimyocardial peak systolic strain and strain rate in healthy Labrador retriever dogs. Research in Veterinary Science. 95(1): 241-248.

10 Chetboul V. 2002. Tissue Doppler imaging: a promising technique for quantifying regional myocardial function. Journal of Veterinary Cardiology. 4(2): 7-12.

11 Chetboul V., Serres F., Gouni V., Tissier R. \& Pouchelon J.L. 2008. Noninvasive assessment of systolic left ventricular torsion by 2 dimensional speckle tracking imaging in the awake dog: Repeatability, reproducibility, and comparison with tissue Doppler imaging variables. Journal of Veterinary Internal Medicine. 22(2): 342-350.

12 Chetboul V. 2010. Advanced techniques in echocardiography in small animals. Veterinary Clinics: Small Animal Practice. 40(4): 529-543.

13 Chetboul V., Bussadori C. \& Madron E. 2016. Normal echocardiographic values: TM, 2D, and Doppler spectral modes. In: Chetboul V. (Ed). Clinical Echocardiography of the Dog and the Cat. St. Louis: Elsevier-Saunders, pp.3137.

14 Chetboul V., Escriou C., Tessier D., Richard V., Pouchelon J.L., Thibault H. \& Derumeaux G. 2004. Tissue Doppler imaging detects early asymptomatic myocardial abnormalities in a dog model of Duchenne's cardiomyopathy. European Heart Journal. 25(21): 1934-1939.

15 Chetboul V. \& Tissier R. 2012. Echocardiographic assessment of canine degenerative mitral valve disease. Journal of Veterinary Cardiology. 14(1): 127-148.

16 D'Andrea A., Cocchia R., Riegler L., Scarafile R., Salerno G., Gravino R. \& Pacileo G. 2010. Left ventricular myocardial velocities and deformation indexes in top-level athletes. Journal of the American Society of Echocardiography. 23(12): 1281-1288. 
17 D’Ascenzi F., Caselli S., Solari M., Pelliccia A., Cameli M., Focardi M. \& Mondillo S. 2016. Novel echocardiographic techniques for the evaluation of athletes' heart: A focus on speckle-tracking echocardiography. European Journal of Preventive Cardiology. 23(4): 437-446.

18 Del Castillo J.M., Herszkowicz N., Boschilia T., Capuano R.L. \& Cortese M.D. 2009. Deformação miocárdica tangencial (shear strain) em indivíduos normais: o seu significado. Revista brasileira de ecocardiografia e imagem cardiovascular. 22(4): 20-26.

19 Demirelli S., Sam C.T., Ermis E., Degirmenci H., Sen I., Arisoy A. \& Simsek Z. 2015. Long-term cardiac remodeling in elite athletes: assessment by tissue Doppler and speckle tracking echocardiography. Echocardiography. 32(9): 1367-1373.

20 Derumeaux G., Ichinose F., Raher M.J., Morgan J.G., Coman T., Lee C. \& Scherrer-Crosbie M. 2008. Myocardial alterations in senescent mice and effect of exercise training: a strain rate imaging study. Circulation: Cardiovascular Imaging. 1(3): 227-234.

21 Hansson K., Häggström J., Kvart C. \& Lord P. 2002. Left atrial to aortic root indices using two-dimensional and M-mode echocardiography in cavalier King Charles spaniels with and without left atrial enlargement. Veterinary Radiology \& Ultrasound. 43(6): 568-575.

22 Helton W. 2009. Physiological demands and adaptations of working dogs. In: Davis M.S. (Ed). Canine Ergonomics: The Science of Working Dogs. Boca Raton: CRC Press. pp.245-262.

23 Kasikcioglu E., Oflaz H., Akhan H., Mercanoglu F. \& Kayserilioglu A. 2003. Tei index and aerobic capacity in endurance athletes. European Journal of Echocardiography. (4): 56.

24 Kovács A., Oláh, A., Lux Á., Mátyás C., Németh B.T., Kellermayer D. \& Assabiny A. 2015. Strain and strain rate by speckle-tracking echocardiography correlate with pressure-volume loop-derived contractility indices in a rat model of athlete's heart. American Journal of Physiology-Heart and Circulatory Physiology. 308(7): 743-748.

25 Lancellotti P., Cosyns B., Zacharakis D., Attena E., Van Camp G., Gach O. \& Piérard L.A. 2008. Importance of left ventricular longitudinal function and functional reserve in patients with degenerative mitral regurgitation: assessment by two-dimensional speckle tracking. Journal of the American Society of Echocardiography. 21(12): 1331-1336.

26 Lombard C.W. \& Spencer C.P. 1985. Correlation of radiographic, echocardiographic, and electrocardiographic signs of left heart enlargement in dogs with mitral regurgitation. Veterinary Radiology \& Ultrasound. 26(3): 89-97.

27 Lonsdale R.A., Labuc R.H. \& Robertson I.D. 1998. Echocardiographic parameters in training compared with nontraining Greyhounds. Veterinary Radiology \& Ultrasound. 39(4): 325-330.

28 Mantovani M.M., Muzzi R.A.L., Pereira G.G., Yamato R.J., Silva A.C., Reis G.F. \& Guimarães E.C. 2015. Systolic cardiac function assessment by feature tracking echocardiography in dogs with myxomatous mitral valve disease. Journal of Small Animal Practice. 56(6): 383-392.

29 Mihl C., Dassen W.R.M. \& Kuipers H. 2008. Cardiac remodelling: concentric versus eccentric hypertrophy in strength and endurance athletes. Netherlands Heart Journal. 16(4): 129-133.

30 Monte I.P., Mangiafico S., Buccheri S., Bottari V.E., Lavanco V., Arcidiacono A.A. \& Tamburino C. 2015. Myocardial deformational adaptations to different forms of training: a real-time three-dimensional speckle tracking echocardiographic study. Heart and Vessels. 30(3): 386-395.

31 Morganroth J., Maron B.J., Henry W.L. \& Epstein S.E. 1975. Comparative left ventricular dimensions in trained athletes. Annals of Internal Medicine. 82(4): 521-524.

32 Moro A.S., Okoshi M.P., Padovani C.R. \& Okoshi K. 2013. Doppler echocardiography in athletes from different sports. Medical Science Monitor. 19: 187.

33 Richand V., Lafitte S., Reant P., Serri K., Lafitte M., Brette S. \& Roudaut R. 2007. An ultrasound speckle tracking (two-dimensional strain) analysis of myocardial deformation in professional soccer players compared with healthy subjects and hypertrophic cardiomyopathy. American Journal of Cardiology. 100(1): 128-132.

34 Rovira S., Munoz A. \& Benito M. 2007. Hematologic and biochemical changes during canine agility competitions. Veterinary Clinical Pathology. 36(1): 30-35.

35 Silva A.P. 2011. Deformação miocárdica em atletas de diferentes modalidades - Um estudo por 2D Speckle Tracking. 98f. Lisboa. Dissertação (Mestrado em Ultrassonografia Cardiovascular) - Programa de Pós-graduação em Tecnologia de Diagnóstico e Intervenção Cardiovascular, Escola Superior de Tecnologia da Saúde de Lisboa. 
36 Simsek Z., Gundogdu F., Alpaydin S., Gerek, Z., Ercis S., Sen I. \& Karakelleoglu S. 2011. Analysis of athletes' heart by tissue Doppler and strain/strain rate imaging. The International Journal of Cardiovascular Imaging. 27(1): 105-111.

37 Simsek Z., Hakan Tas M., Degirmenci H., Gokhan Yazıcı A., Ipek E., Duman H. \& Senocak H. 2013. Speckle tracking echocardiographic analysis of left ventricular systolic and diastolic functions of young elite athletes with eccentric and concentric type of cardiac remodeling. Echocardiography. 30(10): 1202-1208.

38 Smith D.N., Bonagura J.D., Culwell N.M. \& Schober K.E. 2012. Left ventricular function quantified by myocardial strain imaging in small-breed dogs with chronic mitral regurgitation. Journal of Veterinary Cardiology. 14(1): 231-242.

39 Starling E.H. \& Visscher M.B. 1927. The regulation of the energy output of the heart. The Journal of Physiology. 62(3): 243-261.

40 Stepien R.L., Hinchcliff K.W., Constable P.D. \& Olson J. 1998. Effect of endurance training on cardiac morphology in Alaskan sled dogs. Journal of Applied Physiology. 85(4): 1368-1375.

41 Storteig Horn S., Steinheim G., Fjerdingby O.H., Gjerjordet H.F. \& Klemetsdal G. 2017. Genetic analyses of herding traits in the Border Collie using sheepdog trial data. Journal of Animal Breeding and Genetics. 134(2): 144-151.

42 Szauder I., Kovács A. \& Pavlik G. 2015. Comparison of left ventricular mechanics in runners versus bodybuilders using speckle tracking echocardiography. Cardiovascular Ultrasound. 13(1): 7.

43 Takano H., Fujii Y., Yugeta N., Takeda S. \& Wakao Y. 2011. Assessment of left ventricular regional function in affected and carrier dogs with Duchenne muscular dystrophy using speckle tracking echocardiography. BMC Cardiovascular Disorders. 11(1): 23.

44 Tei C. 1995. New noninvasive index for combined systolic and diastolic ventricular function. Journal of Cardiology. 26: $135-136$.

45 Teichholz L.E., Kreulen T., Herman M.V. \& Gorlin R. 1976. Problems in echocardiographic volume determinations: echocardiographic-angiographic correlations in the presence or absence of asynergy. American Journal of Cardiology. 37(1): 7-11.

46 Troy B.L., Pombo J. \& Rackley C.E. 1972. Measurement of left ventricular wall thickness and mass by echocardiography. Circulation. 45(3): 602-611.

47 Tüzün N., Ergün M., Alioğlu E., Edem E., Tengiz I., Aytemiz F. \& İşleğen Ç. 2015. TEI Index in elite sprinters and endurance athletes. The Journal of Sports Medicine and Physical Fitness. 55(9): 988-994.

48 Utomi V., Oxborough D., Ashley E., Lord R., Fletcher S., Stembridge M. \& Sharma S. 2014. Predominance of normal left ventricular geometry in the male 'athlete's heart'. Heart. 100(16): 1264-1271.

49 Wang Y., Wisloff U. \& Kemi O.J. 2010. Animal models in the study of exercise-induced cardiac hypertrophy. Physiological Research. 59(5): 633.

50 Wess G., Keller L.J., Klausnitzer M., Killich M. \& Hartmann K. 2011. Comparison of longitudinal myocardial tissue velocity, strain, and strain rate measured by two-dimensional speckle tracking and by color tissue Doppler imaging in healthy dogs. Journal of Veterinary Cardiology. 13(1): 31-43.

51 Williams T. 2007. Natural ability and selection. In: Working Sheep Dogs: A Practical Guide to Breeding, Training and Handling. Melbourne: Landlinks Press, pp.7-63.

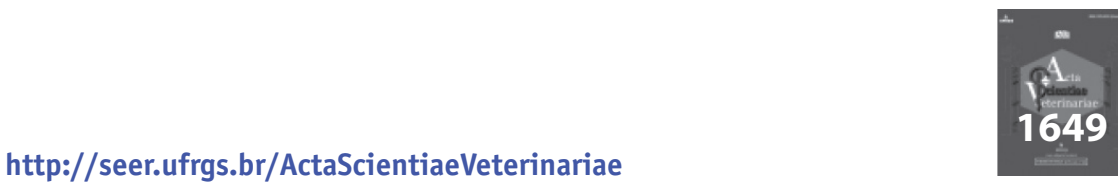

